Check for updates

The BMJ

Cite this as: $B M J 2020 ; 370: m 3789$ http://dx.doi.org/10.1136/bmj.m3789 Published: 29 September 2020

\section{Covid-19: Universities roll out pooled testing of students in bid to keep campuses open}

\author{
Elisabeth Mahase
}

Some UK universities are introducing covid-19 screening programmes using pooled testing to help prevent outbreaks and allow campuses to stay open.

The University of Cambridge and the University of Nottingham are both using pooled testing, which involves mixing several samples together and then testing the pooled sample. If the result comes back positive the people in the group then need to be tested individually.

This approach increases the number of people who can be tested using the same amount of resources-saving time, supplies, and money. However, some experts have raised concerns over whether the costs, benefits, and harms of such programmes have been evaluated, and they have called for advice from the UK National Screening Committee.

In July, Stanford Health Care in the US began using a pooling method for covid-19 (in groups of four to eight), which had previously been used to screen blood donations for the presence of HIV or hepatitis. The group has said that the method is not being used for all samples, as it works best in populations where most samples are expected to be negative.

Pooled testing has also been used in countries including Uruguay and Rwanda, to allow screening of teachers and healthcare workers and to overcome infrastructure and financial issues. ${ }^{1}$

\section{Complex intervention}

Guidance from the University of Cambridge said that all students living in college accommodation would be eligible to take part in its scheme, ${ }^{2}$ which has a capacity of 2000 tests a week and can test around 16 ooo students using the pooling method. This means that all students living in college accommodation can be tested every week.

The guidance said, "Compared with other members of the population, young adults have a higher chance of asymptomatic infection. Public health experts have therefore called for asymptomatic screening in high risk settings, such as universities. As well as protecting students directly, controlling transmission between students will help prevent onward transmission to staff and the wider Cambridge community."

However, there are downsides to pooling. The US Food and Drug Administration says that, because the samples are diluted, pooling can "result in less viral genetic material available to detect" and a greater likelihood of false negative results. ${ }^{3}$

Allyson Pollock, professor of public health and co-director of the Newcastle University Centre of
Research Excellence in Regulatory Science, told The $B M J$, "The UK National Screening Committee should be consulted and involved with this, because screening is a very, very complex public health intervention. It should be carefully evaluated so that we know what the costs, harms, and benefits are, because screening like this will be extremely costly."

Pollock has raised concerns over the potential for many false positives, as well as the inability of current testing technology to determine infectiousness. "You could end up quarantining students and staff and their contacts and their whole households unnecessarily and causing a lot of hardship," she said, adding that the financial harm this could cause to students-many of whom will be working-must also be considered.

Despite these concerns Independent SAGE has recommended regular testing of students and staff. ${ }^{4}$ In a report on universities published on 28 September the group called for all staff and students to be tested at the start of the academic year, before initiating any in-person contact. Institutions should also "initiate structured surveillance programmes for high risk settings such as residential halls of residence-this could include innovative approaches such as sewage testing, pooled sample testing, as well as random sampling," the document said.

Andrew Fogarty, clinical associate professor and reader in clinical epidemiology at the University of Nottingham, said that the pooling method could also be used for regular screening of healthcare workers and was being considered by Nottingham University Hospitals NHS Trust. He said that, during the first wave, $20-30 \%$ of trust staff were either off work because of a confirmed infection or isolating because they were showing symptoms.

"With a second wave approaching, we were looking to see what we could do to try and learn from the first experience and protect the staff," he said. "The problem is that there's not really much excess testing capacity. So, we looked at the literature and came up with this idea of pooled testing. We then put together a protocol which we have sent to the NHS board, and it's being considered."

Taylor L. Uruguay is winning against covid-19. This is how. BM] 2020;370:m3575. doi: 10.1136/bmj.m3575 pmid: 32948599

2 Stay Safe Cambridge Uni. Weekly asymptomatic screening programme for COVID-19 at the University of Cambridge. Updated 25 Sep 2020. https://www.cam.ac.uk/coronavirus/stay-safe-cambridge-uni/get-tested\#asymptomatic

US Food \& Drug Administration. Pooled sample testing and screening testing for covid-19. 28 Aug 2020. https://www.fda.gov/medical-devices/coronavirus-covid-19-and-medical-devices/pooled-sample-testingand-screening-testing-covid-19. 
4 Independent SAGE emergency statement on universities in the context of rising SARS-CoV-2 cases in late September 2020. 28 Sep 2020. https://www.independentsage.org/independentsage-emergency-statement-on-universities-in-the-context-of-rising-sars-cov-2-cases-in-lateseptember-2020/.

This article is made freely available for use in accordance with BMJ's website terms and conditions for the duration of the covid-19 pandemic or until otherwise determined by BMJ. You may use, download and print the article for any lawful, non-commercial purpose (including text and data mining) provided that all copyright notices and trade marks are retained. 